\title{
The Incidence of Isolated Ventricular Septal Defect in Libyan Newborns
}

\author{
Mohamed Thabet Ali ${ }^{*}$ and Faiza Mohamed Ali \\ Department of Pediatrics, Faculty of Medicine Omar Al-Mukhtar University, Al-Bayda - Libya
}

Received: 01 March 2021/ Accepted: 28 April 2021

Doi: https://doi.org/10.54172/mjsc.v36i2.59

\begin{abstract}
This study aimed to evaluate the incidence and spontaneous closure of ventricular septal defects in a randomly selected newborn population, using color Doppler echocardiographic screening. Color flow Doppler echocardiographic screening was performed in 635 neonates within the first week of life. Patients with a ventricular septal defect were also followed up for 6 months to detect spontaneous closure rate and its timing. The incidences of a ventricular septal defect in all neonates, preterm neonates, and term neonates were found as 48.8/1,000, 64/1,000, and 48.1/1,000 live births, respectively. Only three patients were symptomatic. 21 cases had a muscular ventricular septal defect and 10 cases had a perimembranous ventricular septal defect. Most of them had a small ventricular septal defect $(\leq 3 \mathrm{~mm})$. Spontaneous closure was observed in $64.5 \%$ of ventricular septal defects within 6 months Closure rate was found as $80 \%$ for preterm infants and $66.8 \%$ for term infants ( $>0.05)$. The incidence of a ventricular septal defect was considerably high in neonates when routine color flow Doppler echocardiographic examination was performed. Despite the increased incidence of ventricular septal defect, spontaneous closure rate was remarkably high within the first 6 months of life. These defects may result from delayed physiologic development and have a good prognosis.
\end{abstract}

Keywords: Echocardiography, Newborn, Ventricular Septal Defect, Incidence

\section{INTRODUCTION}

A ventricular septal defect is the most common form of CHD and accounts for $15 \%$ to $20 \%$ of all such defects, not including those occurring as part of cyanotic CHDs. The defects vary in size, ranging from tiny defects without hemodynamic significance to large defects with accompanying CHF and pulmonary hypertension (Park, 2014). After using color Doppler echocardiography, the incidence of ventricular septal defects (VSDs) has been reported in some studies to be higher than 7/1000 live birth (Hiraishi et al., 1992). In some of these studies, the incidence of muscular VSD was examined in full-term (Roguin et al., 1995) or preterm neonates (Du et al., 1996) and neonates having a low risk for the development of VSD (Sands et al., 1999). They concluded that the incidence of VSD might have been underestimated in the past. The increasing preterm delivery, environmental factors, or better echocardiographic imaging due to evolving technology may be responsible for the increase in the reported incidence of VSD. Data regarding the epidemiology of VSD is very limited and depends on a few epidemiological studies (Clark, 2001).

Thus, this study was designed to evaluate the incidence of VSD in a randomly selected preterm and full-term newborn population, using color Doppler echocardiographic screening. Also, the study intended to follow-up patients with VSD for a year to detect the rate and timing of spontaneous closure.

\section{MATERIALS AND METHODS}

All live newborns delivered in the Obstetrics Department of Albayda Hospital and kept in

*Corresponding Author: Mohamed Thabet Ali kwafi65@yahoo.com , Department of Pediatrics, Faculty of Medicine Omar Al-Mukhtar University, Albaida - Libya 
the nursery for more than one day in the period from April 2018 to December 2018 were included in the study group. Parental consents were obtained from the parents of each neonate. A detailed history of the neonates, parents, and family members was taken by interviewing the parents. Clinical characteristics of cases with VSD were compared with neonates without congenital heart defect (CHD). 635 (320 M, 315 F) were included in the study. There were 540 (85\%) full-term and 77(12.1\%) preterm (gestational age $<37$ weeks) infants. Their gestational ages ranged from 30 to 42 weeks Echocardiographic studies were performed in all neonates within the first week in the Department of Pediatric in Albayda Hospital. Complete trans-thoracic two-dimensional, M-mode, continuous wave and pulsed wave Doppler and color Doppler echocardiographic examinations were performed in all cases followed by a thorough physical examination. Echocardiographic examination was performed using Toshiba Xario cardiac imager.

The diagnosis of a VSD was established based on the presence of a mosaic image passing anywhere through the ventricular septum from the left ventricle to the right ventricle, and a turbulent systolic flow jet recorded on the right surface of the VSD by pulsed or continuous wave Doppler. The diameter of VSD in twodimensional and/or color flow mapping was measured in all planes and the largest diameter of VSD was recorded. Apical four-chamber, parasternal long- and short-axis, and subcostal positions were used to image the defect. The defects were classified according to previously defined criteria (Snider et al., 1997). Infants who had associated complex structural cardiovascular defects were excluded from the isolated VSD group in neonates with VSD, echocardiography was repeated at the $1^{\text {st }}, 3^{\text {rd }}, 6^{\text {th }}$ months of age or until the spontaneous closure of the VSD was confirmed. The chi-square test was used to compare the differences where appropriate. A p value less than 0.05 was considered statistically significant.

\section{RESULTS}

A ventricular septal defect was found in 31 of 635 neonates, at an incidence of 48.8 in 1,000 live births. 26 of them were full-term and 5 were preterm infants. The incidences of VSD in full-term and preterm neonates were 48.1 in 1,000 live births (26/540 cases) and 64 in 1,000 live births (5/77 cases), respectively. There was no statistical difference in the incidence of VSD between full-term and preterm infants $(p=0.52)$. By echocardiographic screening, other CHDs were identified in 27 neonates. Atrial septal defect, bicuspid aortic valve, and patent ductus arteriosus were detected in 13 , and 7 cases, respectively.

Tetralogy of Fallot (3 cases), Transposition of great arteries (2 cases), Double outlet right ventricle (1 case), single ventricle (1 case) were also identified. In this study, the first echocardiographic examination of babies was performed within the first week after birth. Patent ductus arteriosus was also detected in 213 babies within the first week after birth. At the end of the first year of life, it was observed that patent ductus arteriosus persisted in only 7 of them. Gestational age, birth weight, and sex distribution of cases with VSD were not different from neonates without CHD (Table 1). By echocardiography, 21cases $(67.7 \%)$ had a muscular VSD (14 located at the apical region, 7 located at the mid-muscular region and 10 cases $(32 / 2 \%)$ had perimembranous VSD. 25 cases had single and 6 cases (19.3\%) had 2 VSDs. Thus, 37 VSDs were detected in 31 neonates. Defect sizes ranged from 1 to $7 \mathrm{~mm}$ in diameter VSDs detected in preterm neonates were all small-sized and located in the muscular region. Only 7 of 37 VSDs were detected by using two- dimensional imaging solely. However, all defects were easily recognized after using color Doppler echocardiographic imaging. 2 cases did not present for follow-up examinations after the first visit. The remaining 29 cases with VSD were followed up during 6 months. 9 of them had a peri-membranous and 20 of them had a muscular VSD. 6 of them had 2 VSDs. 
Except for 3; all had small-sized VSD. Spontaneous closure was recorded in 20 of $31(64.5 \%)$ of VSDs.

Table: (1) Clinical Characteristics of Neonates with Ventricular Septal Defect

\begin{tabular}{lcll}
\hline \hline & $\begin{array}{c}\text { neonates with } \\
\text { ventricular } \\
\text { septal } \\
\text { defect(n=31) }\end{array}$ & $\begin{array}{c}\text { Neonates without } \\
\text { ventricular } \\
\text { heart defect }(\mathrm{n}=604)\end{array}$ \\
\cline { 2 - 4 } & $\begin{array}{c}\text { No. of } \\
\text { cases(\%) }\end{array}$ & $\begin{array}{c}\text { No. of } \\
\text { cases(\%) }\end{array}$ & p value \\
\hline $\begin{array}{l}\text { Gestational } \\
\text { age (weeks) }\end{array}$ & $38.3 \pm 1.8$ & $38.2 \pm 1.9$ & 0.5 \\
$\begin{array}{l}\text { Sex } \\
\text { (female/male) }\end{array}$ & 1.31 & 0.80 & 0.11 \\
$\begin{array}{l}\text { Birth weight } \\
\text { (gram) }\end{array}$ & $3125 \pm 540$ & $\begin{array}{l}3150 \\
\pm 550\end{array}$ & 0.66 \\
$\begin{array}{l}\text { Maternal age } \\
\text { (year) }\end{array}$ & $28.7 \pm 4$ & $28.3 \pm 5$ & 0.8 \\
\hline \hline
\end{tabular}

Figure: (1). Ventricular Septal Defect Location

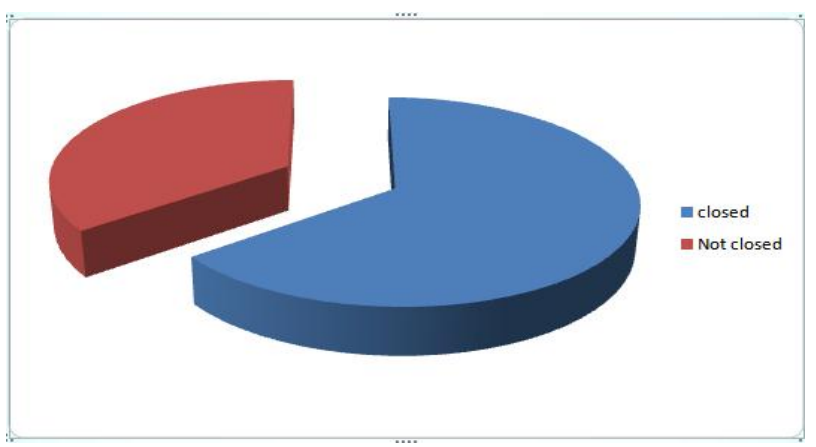

Figure: (2). Spontenous closure in first 6 months of life

\section{DISCUSSION}

The incidence of VSD in term newborn infants varies from 20.4 to 53.2/1,000 live births (Sands et al., 1999) Like these studies, it was observed that the incidence of VSD was con- siderably high in full-term infants when routine color flow Doppler echocardiographic examination was performed. Du reported that the prevalence of muscular VSD in preterm infants was 56.6/ 1,000 live births (Du et al., 1996), in this work, the incidence of VSD in all neonates and full-term neonates was similar to rates in Sands and Roguin studies. The incidence of VSD in preterm infants in the current study was also higher than the rate reported by $\mathrm{Du}$ (Du et al., 1996). In the current study, the incidence of VSD in full-term and preterm newborns was not found to be statistically different. Therefore, in contrast to previous thought, it could not be shown that increasing preterm delivery was responsible for the increasing incidence of VSD. Color flow Doppler echocardiographic screening is the most reliable method for assessing true incidences of VSD and detects neonates with VSD even in cases without murmur.

\section{CONCLUSION}

It was concluded in this study that $64.5 \%$ of cases closed spontaneously within six months of life. If newborns were preselected by physical examination for echocardiographic examination, the incidence of VSD would have been lower than what was determined. Major factors influencing the spontaneous closure rate of VSDs are the patient's age at the first examination, localization, and size of the defects. By color flow Doppler echocardiography, Closure was seen in $86.5 \%$ of muscular VSDs. These results were similar to those of (Du et al., 1998; Miyake et al., 2004)'s studies. The other $13.5 \%$ were not closed at the time of this study and followed beyond that time. The current study also could not show a difference_in spontaneous closure rate of VSD between full-term and preterm neonates, as in (Roguin et al., 1995)'s study. The current study showed that the incidence of VSD was considerably high in fullterm and preterm neonates when routine color flow Doppler echocardiographic examination was performed. Despite the increased incidence of VSD, most patients' VSD was clinically insignificant and the spontaneous closure rate (C) 2021 The Author(s). This open access article is distributed under a CC BY-NC 4.0 license. ISSN: online 2617-2186 print 2617-2178 
was remarkably high within the first six months of life. Thus, this study concludes that these defects may be the consequence of delayed physiological development and have a fairly good prognosis. Indeed, since the majority of tiny VSDs may either close spontaneously or never cause medical problems, patients with small VSD do not need specialized cardiologic care (Hoffman \& Kaplan, 2002). The current study also conclude that routine echocardiographic screening in all neonates without clinical findings is not necessary, except in neonates with a familial history of CHD or having well-defined risk factors.

\section{REFERENCES}

Clark, E. B. (2001). Etiology of congenital cardiovascular malformations: epidemiology and genetics. Moss and Adams' Heart Disease in Infants and Adolescents, 1, 64-79.

Du, Z.-D., Roguin, N., Barak, M., Bihari, S. G., \& Ben-Elisha, M. (1996). High prevalence of muscular ventricular septal defect in preterm neonates. The American journal of cardiology, 78(10), 1183-1185.

Du, Z.-D., Roguin, N., \& Wu, X.-J. (1998). Spontaneous closure of muscular ventricular septal defect identified by echocardiography in neonates. Cardiology in the young, 8(4), 500-505.

Hiraishi, S., Agata, Y., Nowatari, M., Oguchi, K., Misawa, H., Hirota, H., Fujino, N., Horiguchi, Y., Yashiro, K., \& Nakae, S. (1992). Incidence and natural course of trabecular ventricular septal defect: two-dimensional echocardiography and color Doppler flow imaging study. The Journal of pediatrics, 120(3), 409-415.

Hoffman, J. I., \& Kaplan, S. (2002). The incidence of congenital heart disease. Journal of the American College of Cardiology, 39(12), 1890-1900.
Miyake, T., Shinohara, T., Nakamura, Y., Fukuda, T., Tasato, H., Toyohara, K., \& Tanihira, Y. (2004). Spontaneous closure of ventricular septal defects followed up from $<3$ months of age. Pediatrics international, 46(2), 135140.

Park, M. (2014). Park's pediatric cardiology for practitioners, ser. Pediatrics. Philadelphia, PA: Elsevier Saunders.

Roguin, N., Du, Z.-D., Barak, M., Nasser, N., Hershkowitz, S., \& Milgram, E. (1995). High prevalence of muscular ventricular septal defect in neonates. Journal of the American College of Cardiology, 26(6), 1545-1548.

Sands, A., Casey, F., Craig, B., Dornan, J., Rogers, J., \& Mulholland, H. (1999). Incidence and risk factors for ventricular septal defect in "low risk" neonates. Archives of Disease in Childhood-Fetal and Neonatal Edition, 81(1), F61-F63.

Snider, A., Serwer, G., \& Ritter, S. (1997). Echocardiography in Pediatric Heart Disease, Mosby-Year Book. Inc., St. Louis, Missouri, 29. 


\section{نسبة حدوث ثقب الجدار البطيني المتفرد في الأطفال الليبيين حديثي الولادة \\ محمد ثابت علي * وفائزة محمد علي

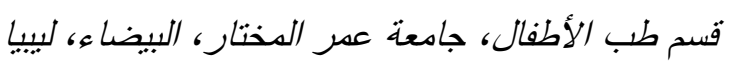

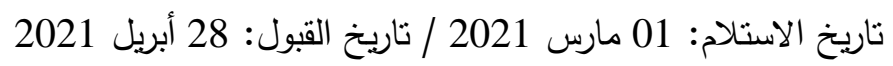
https://doi.org/10.54172/mjsc.v36i2.59:Doi

المستخلص : هدفت هذه الدراسة إلى تقييم معدل حدوث عيوب الحاجز البطيني، والإغلاق التلقائي لعيوب الحاجز البطيني في

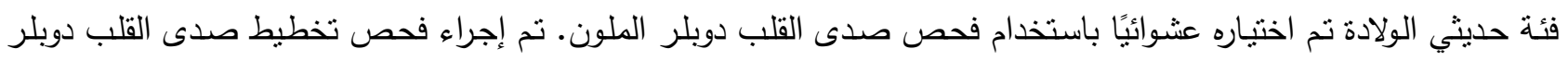

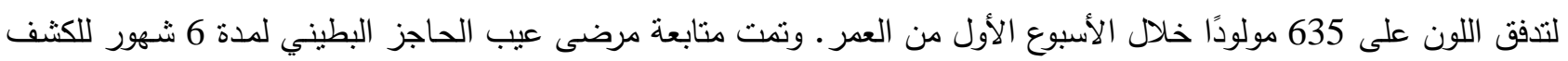

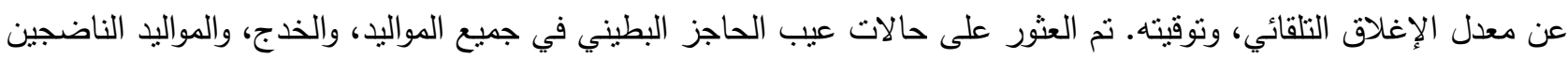

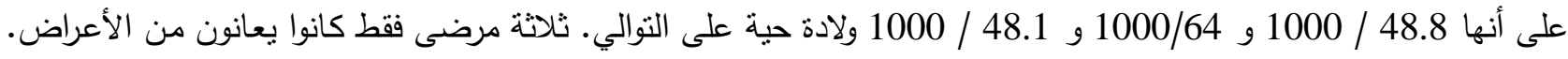

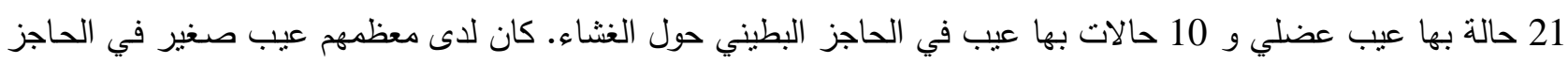

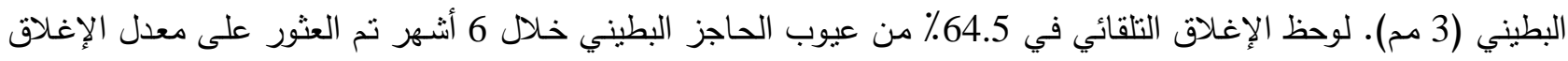

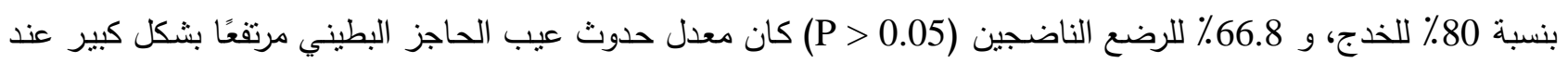

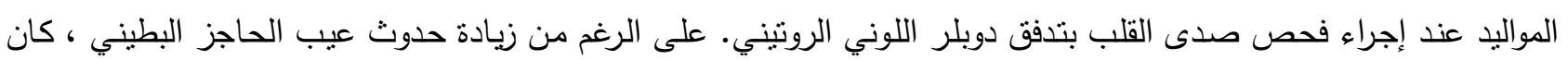

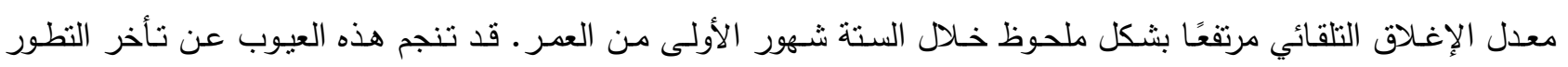
الفسيولوجي، ويكون لها تشخيص، وتوقعات جيدة للمستقبل.

الكلمات المفتاحية : تخطيط صدى القلب ، حديثي الولادة ، عيب الحاجز البطيني ، معدل الإصابة. 